\title{
Effect of blank samples on absolute odor threshold determinations'
}

\author{
G. STEINMETZ, G. T. PRYOR, AND H. STONE ${ }^{2}$ \\ STANFORD RESEARCH INSTITUTE
}

\begin{abstract}
Absolute odor thresholds for methyl isobutyl ketone were estimated under five conditions: odor sample-to-air blank ratios of $1: 2,1: 1,2: 1,4: 1$, and 9:1. Each of the five ratios was presented in two replicated balanced Latin square sequences to five adult human Ss. The results showed that significantly lower estimates of the threshold were obtained when the ratio of odor samples to air blanks was 1:1. These results are discussed in terms of possible adaptation effects, maintenance of an internal frame of reference as a basis for decisions, and response matching to pay-off expectancy.
\end{abstract}

In the investigation of olfactory phenomena, it is often necessary to establish absolute thresholds for an odorant, as reference values for each S. Previously, a tracking procedure, in which stimulus intensities right around the S's threshold are randomly presented, was found to be very useful for this purpose (Stone et al, 1967). As with most psychophysical methods of this sort, blank samples of background air are randomly inserted to correct for false positives and to ensure that the Ss and apparatus are functioning properly. It was suspected that the ratio of blank samples to odor samples in this or any similar procedure would yield different estimates of the absolute threshold due to the sequential nature of the stimulus presentations. There is the possibility that factors such as adaptation, residual odors, response set, etc., resulting from one stimulus presentation might have an artifactual effect on any subsequent stimulus presentation. Depending on the factor(s) involved, the threshold would be altered accordingly. We hypothesized that a decrease in the estimated threshold would occur in proportion to increases in blank samples inserted. The rationale for this hypothesis was that an absolute threshold detection, in effect, requires a $S$ to differentiate "something from nothing." The more of ten he has an opportunity to compare a sample of "nothing," the more contrasting and the more prominent would be the appearance of "something" (a stimulus). Moreover, with a larger number of blank samples there would be less chance for adaptation to occur and the possibility of residual odorant molecules from previous trials would be minimized.

\section{Subjects}

\section{METHOD}

Subjects were three male and two female adult humans employed at the Institute and chosen on the following basis: (a) absence of obvious olfactory aberrations (nasal diseases, allergies) and (2) reliable performance in odor detection in two or more pilot sessions prior to experimental testing. They were instructed to refrain from using perfumes or after-shave lotions on test days and from eating, smoking, or chewing gum for at least $30 \mathrm{~min}$ before each test session.

\section{Apparatus}

The olfactometer is an air-dilution system based on equipment described elsewhere (Stone \& Bosley, 1965) and recently modified to allow semiautomated operation. ${ }^{3}$ Air, supplied in excess of $20 \mathrm{cfm}$ by a high-speed blower, is passed over a refrigeration coil. A portion of this cooled air is picked up by a small, highspeed blower, and passed over a rheostat-controlled heating coil and through an activated-carbon filter bed into a glass tubing system. This "odor-free," temperature-controlled air flows continuously through a series of regulating valves and a flowmeter (Fisher-Porter, $14.6 \mathrm{cfm}$ capacity) and, ultimately, into a five-sided Plexiglas hood. The S's head is positioned in the hood. Delivery of a stimulus to $S$ is accomplished by metering high-purity, water-pumped $\mathrm{N}_{2}$ through one of a series of four precision flowmeters into a diffusion bulb. The gas is saturated by passing it through a sintered-glass sparger immersed in the stimulus. This saturated vapor then passes through a timercontrolled, three-way, solenoid valve en route to the main air stream. When the stimulus is presented, the valve permits the odor-saturated vapor to proceed for a preset time into the mixing chamber of the main air stream, about 6 to 8 in. "upstream" from the outlet into the Plexiglas hood. During the intertrial in terval, the valve is positioned so that any residual odorant vapor is vented through the ceiling to the outside atmosphere.

Temperature of the stimulus was maintained at $25 \mathrm{deg} \pm 0.25 \mathrm{deg} C$ by means of a thermistor-regulated water bath.

Communication between $\mathrm{E}$ and $\mathrm{S}$ during testing was through light panels positioned in front of each; a partition prevented $S$ from seeing $E$. A light signaled $S$ that a trial had begun, and $S$ indicated whether he thought a stimulus was present or absent by pressing the appropriate button in front of him. After $S$ responded, another light signaled to $S$ whether an odor was actually present on that trial. In all test series, each stimulus was presented for $5 \mathrm{sec}$, with a 20 -sec interval between presentations. Both periods were electronically timed and automatically controlled by the solenoid switches.

Concentrations of the odorant delivered to $S$ were calculated from the vapor pressure, the experimental temperature, and the flow rates of the gas, in accordance with previously established procedures (Stone, 1963).

\section{Test Odorant}

The odorant tested was methyl isobutyl ketone. Purity of the stimulus was in excess of $99 \%$ and assured by redistillation; only the constant boiling fraction was used.

\section{Test Procedures}

Absolute thresholds were estimated twice for each $\mathbf{S}$ under five conditions of odor samples-to-air blank ratios. The ratios were $1: 2$ (one odor sample per two air blank samples) $1: 1,2: 1,4: 1$, and 9:1 (nine odor samples per blank sample). The order of estimation of the thresholds under the five ratio conditions was balanced across $\mathrm{Ss}$ in a Latin square design. The experiment was replicated using the same Ss. Thus, each S provided 10 threshold estimates -2 for each of the five ratio conditions. Each threshold estimate consisted of 50 trials, using the random tracking procedure described earlier (Stone et al, 1967), and required approximately $25 \mathrm{~min}$; one or two threshold estimates were obtained per test session as S's work schedule permitted. Testing covered 10 days. On each trial, $S$ signaled only "odor detected" or "odor not detected"; he was informed in turn by $\mathrm{E}$ whether 
Table 1

Threshold ( $\left.\mathrm{I}_{\mathrm{t}}\right)^{*}$ Means and Analysis for Subjects, Order of Presentation and Odor/Blank Ratio for Methyl Isobutyl Ketone

\begin{tabular}{|c|c|c|c|c|c|c|c|c|c|c|c|}
\hline \multirow{3}{*}{$\mathbf{S}$} & \multicolumn{2}{|r|}{ Subjects } & \multicolumn{6}{|c|}{ Presentation Order } & \multicolumn{3}{|c|}{ Odor/Blank Ratio } \\
\hline & & Replication & Overall & & Repl & & Overall & & Repl & ation & Overall \\
\hline & 1 & 2 & & Order & 1 & 2 & & Ratio & 1 & 2 & \\
\hline NT & 13.7 & 14.9 & $14 ; 3$ & 1st & 14.8 & 12.1 & 13.4 & $9: 1$ & 13.1 & 13.4 & 13.2 \\
\hline JK & 6.3 & 8.1 & 7.2 & 2nd & 12.8 & 12.8 & 12.8 & $4: 1$ & 12.7 & 12.3 & 12.5 \\
\hline DJ & 9.8 & 10.8 & 10.3 & $3 r d$ & 10.6 & 11.1 & 10.1 & $2: 1$ & 12.0 & 12.3 & 12.2 \\
\hline MS & 13.7 & 14.8 & 14.3 & 4th & 10.3 & 12.7 & 11.5 & $1: 1$ & 10.3 & 11.0 & 10.7 \\
\hline RH & 16.0 & 13.1 & 14.6 & 5th & 11.1 & 13.0 & 12.1 & $1: 2$ & 11.4 & 12.7 & 12.1 \\
\hline $\begin{array}{l}\text { df } \\
F\end{array}$ & $\begin{array}{l}4 / 20 \\
12.91\end{array}$ & $\begin{array}{l}4 / 20 \\
16.87\end{array}$ & $\begin{array}{r}4 / 45 \\
23.83\end{array}$ & $\begin{array}{l}\text { df } \\
F\end{array}$ & $\begin{array}{l}4 / 12 \\
10.5\end{array}$ & $\begin{array}{c}4 / 12 \\
1.57\end{array}$ & $\begin{array}{l}4 / 28 \\
3.66\end{array}$ & $\begin{array}{l}\mathrm{df} \\
\mathrm{F}\end{array}$ & $\begin{array}{c}4 / 12 \\
3.61\end{array}$ & $\begin{array}{c}4 / 12 \\
2.51\end{array}$ & $\begin{array}{l}4 / 28 \\
3.13\end{array}$ \\
\hline p & $<.001$ & $<.001$ & $<.001$ & p & $<.001$ & NS & $<.025$ & p & $<.05$ & $<.10$ & $<.05$ \\
\hline
\end{tabular}

*All means expressed as concentrations of odorant $\left(x 10^{-7} \mathrm{~g} /\right.$ liter of air $)$

"odor was present" or "odor was absent" on that trial. No attempt was made by $S$ to otherwise identify odors or blanks, and feedback from $E$ contained no value connotation such as "right/wrong" or "correct/incorrect."

\section{RESULTS}

Table 1 summarizes the data for inter-S differences, order of presentation, and the ratio of odor samples to blanks. Analyses of variance were carried out for each replication separately and for the combined means. Differences among Ss were highly significant and consistent in both replications. An indication of high test reliability was the very small number of false positives reported for blank samples $(<3 \%)$. The order of presentation was significant in the first replication but not in the second, suggesting a learning effect over the first few test sessions as the threshold estimates tended to decrease from the first to the fifth test session. Similar results have been observed previously. ${ }^{4}$ The ratio of odor samples to air samples generally decreased the threshold estimates as the ratio of the number of air blanks increased to $1: 1$. This trend was reversed, however, when two blanks to one odor sample were used. This result was statistically significant for the combined analysis and for the first replication. The second replication exhibited the same trend but did not reach a level of significant $(<.10)$. Further comparisons using the residual error variance from the combined analysis (modified " $q$ " statistic, Winer, 1962) showed that only the 1:1 ratio resulted in a mean threshold estimate that was significantly lower than any of the other means $(\mathrm{p}<.05-.01)$.

Table 2 shows the effects of preceding stimulus strength on detected threshold stimuli. At each threshold level (50\% limen), detected stimuli were preceded on the average by weaker stimuli than those at threshold level that were not detected; however, none of the differences reached an acceptable level of significance when tested by separate t-tests.

The mean threshold value for the panel was $12.13 \times 10^{-7} \mathrm{~g} / 1$, which is in good agreement with previously reported results from our laboratory, $9.73 \times 10^{-7} \mathrm{~g} / 1$ (Stone et al, 1967).

\section{DISCUSSION}

The results of this experiment suggest that the absolute threshold for odor detection can be manipulated by changing the content of the stimuli surrounding any particular test stimulus, and thus point up the caution that must be exercised in its estimation. There are in the present experiment at least three ways such an effect could occur: (1) A given odorant stimulus could reduce receptor sensitivity for the following stimulus (adaptation), tending to produce higher thresholds in those series containing fewer air blanks. (2) $\mathrm{S}$ is required to distinguish between the presence of odor ("something") and the absence of odor ("nothing"), and in an experiment such as this, which provides feedback as to "odor present" or "odor absent," he may form a more accurate frame of reference in those series providing more blanks. As in (1), higher thresholds would be expected in those series containing fewer blanks and offering less opportunity to remember what a blank smells like. (3) Finally, the phenomenon of response-matching to pay-off expectancy has been well established (Green \& Swets, 1966) and thus it might also be predicted that $S$ would report positively (detect odor) in direct proportion to the ratio of odor stimuli in the series. Such behavior would produce an effect opposite to that expected from (1) and (2) and what was actually observed, in that lower thresholds would be expected in those series containing fewer air blanks.

Considering our results only in terms of the first two hypotheses, then, the following is indicated:

(1) The overall trend of increasing the ratio of blanks to odor samples producing lower thresholds suggests adaptation effects. This hypothesis is strengthened by the indication that stimuli immediately preceding nondetected stimuli at threshold level tended to be stronger than those preceding detected threshold stimuli. Thus, an adaptation hypothesis would be consistent with results from four of the experimental ratios but not from the fifth, where the lowest odor-to-blank ratio $(1: 2)$ did not produce the lowest threshold.

(2) A similar difficulty is encountered with this explanation. As originally stated, S's frame of reference would be increasingly optimized by increasing the ratio of blanks to odor samples, where the appearance of an odor stimulus would be more prominent against a background of blanks. As with the adaptation explanation, this would account for the lowering of thresholds in four of the ratios, but not for the last $(1: 2)$, where the number of blank stimuli exceeded odor stimuli and a higher threshold value was obtained. However, if such an optimal frame of reference were not at an extreme condition, then thresholds

Strength of Stimuli* Preceding Detected Threshold Stimuli Compared with Strength of Stimuli Preceding Nondetected Threshold Stimuli

\begin{tabular}{|c|c|c|c|c|c|}
\hline Flowmeter Setting & $\begin{array}{c}\text { Threshold Stimulus } \\
\text { Level }\end{array}$ & $\begin{array}{l}\text { Mean Stimulus Intensity Pre- } \\
\text { ceding Detected Threshold } \\
\text { Stimuli }\end{array}$ & $\begin{array}{l}\text { Mean Stimulus Strength Pre- } \\
\text { ceding Nondetected } \\
\text { Stimuli }\end{array}$ & $\mathbf{t}$ & p \\
\hline 2 & 10.4 & 6.8 & 8.8 & 1.3 & $<.2$ \\
\hline 3 & 13.4 & 7.9 & 10.8 & 1.7 & $<.1$ \\
\hline 4 & 17.1 & 11.0 & 12.5 & 1.2 & $<.3$ \\
\hline
\end{tabular}

* Values in columns 2 to 4 are odor concentrations $\times 10^{-7} \mathrm{~g} /$ liter 
would increase as blank-to-odor ratios varied in either direction from optimal. It seems reasonable to expect that such an optimal ratio might be $1: 1$, where $S$ has more equally and constantly at hand images of both what the odor is like and what the absence of odor is like.

\section{REFERENCES}

GREFN, D. M., \& SWETS, J. A. Signal detection theory and psychophysics. New York: J. Wiley, 1966.

STONE, $\mathrm{H}$. Some factors affecting olfactory sensitivity and odor intensity. Thesis, University of California, Davis, 112 pp., 1963.

STONE, H., \& BOSLEY, J. J. Olfactory discrimination and Weber's Law. Perceptual \& Motor Skills, 1965, 20,657-665.

STONE, H., PRYOR, G., \& COLWELL, J. Olfactory detection thresholds in man under conditions of rest and exercise. Perception \& Psychophysics, 1967, 2, 167-170.
WINER, B. J. Statistical principles in experimental design. New York: McGraw-Hill, 1962 (Newman-Keuls method, pp. 80-81).

\section{NOTES}

1. This research was supported by Grant No. NB07832 from the Institute of Neurological Sciences of the National Institutes of Health to $H$. Stone.

2. Address: Stanford Research Institute, Menlo Park, Califomia 94025. 3. Stone, H., Pryor, G., \& Steinmetz, G. The design and operation of a precision olfactometric system. To be published, 1969.

4. Pryor, G., \& Stone, H. Unpublished laboratory report, Life Sciences Division, Stanford Research Institute, 1968.

(Accepted for publication January 23, 1969.) 